\title{
Design considerations of high-speed eddy-current brake
}

\author{
Tomasz Garbiec, Marcin Kowol, Janusz KolodzIEJ \\ Opole University of Technology \\ Faculty of Electrical, Control and Computer Engineering \\ e-mail: \{t.garbiec/m.kowol/ja.kolodziej\}@po.opole.pl
}

(Received: 07.01.2014, revised: 04.04.2014)

\begin{abstract}
The paper presents results of analysis of the influence of rotor construction on the steady-state torque-speed characteristics of a high-speed eddy-current brake. The investigation is carried out using two- and three-dimensional finite element models and measurements. A series of computations is carried out in order to find out the method for performance improvement of the considered system.
\end{abstract}

Key words: eddy-current brake, end-effect, finite element method

\section{Introduction}

Utilizing a high-speed machine coupled with a driven device directly (without a gear-box) makes possible to achieve higher efficiency and smaller size of the whole drive system while avoiding problems and costs associated with maintaining the gear-box [1]-[6].

A steady-state torque-speed characteristic is one of the most important performance characteristics for every type of electrical machine. Obtaining such a characteristic for high-speed machines is a very complex task, especially when a low-power machine operating at rotational speed above $10000 \mathrm{rpm}$ is considered. This is because there are no torque transducers on the market available for such the applications. A solution of this problem might be utilizing a customized eddy-current brake connected with tangential force transducers [7-11]. This work investigates on such a system designed for the measurement of the low-power hysteresis motor (see Fig. 1, Tab. 1).

In our previous work [12] we presented preliminary results regarding determination of its basic performance. The principle of its operation relies upon measuring the tangential reaction force that acts on the brake armature (equipped with the single-phase, two-pole winding fed with direct current) using tensometric force transducers. The differential signals from the transducers is amplified by the electronic unit in order to obtain the signal proportional to the measured torque [12]. The rotor, made of solid steel, is attached to the motor shaft without mechanical contact with the armature.

The goal of the current analysis is to determine the influence of rotor construction on the steady-state torque-speed characteristics as well as seeking the methods for improving these 
characteristics. It is well-known that the performance of rotating electromechanical converters equipped with solid-rotors, made of ferromagnetic material, might be improved by utilizing simple modifications of the rotor construction such as use of axial slits or coating surface with copper [4]. Influence of those modification on the performance of the solid-rotor induction machines was extensively studied in literature [4, 13, 14]. Due to significant differences between construction of a typical solid-rotor induction machine and the analyzed converter (salient poles, concentrated windings, and much smaller ratio of the rotor length-to-diameter, see Tab. 1) the results of those studies do not apply for the DC-current-fed brakes operating at large slips. In order to investigate influence of the rotor construction on the torque-speed characteristic properly it is necessary to carry out the analysis using a finite-element model.

a)

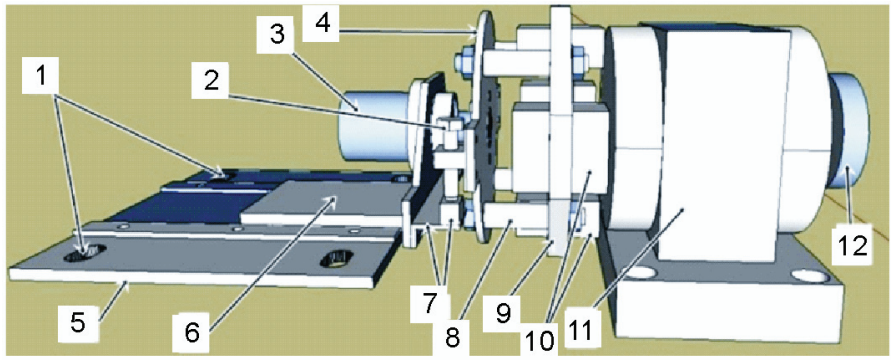

b)

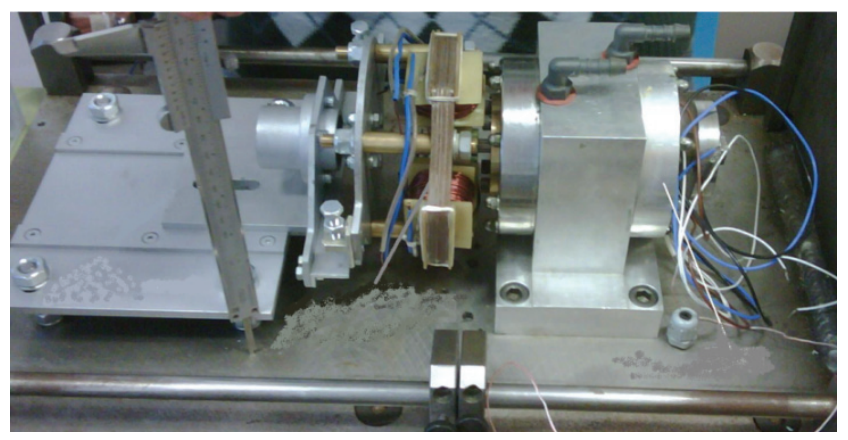

Fig. 1. Eddy-current brake coupled with motor on laboratory test-stand: a) CAD diagram, 1 and 5 - bottom plate, 2 - calibration screw, 3 - rotary support of brake armature, 4 - armature support, 6 - sliding support to decouple motor from brake, 7 - tensometric force transducers, 8 - auxiliary screws, 9 - brake armature, 10 - field coils of brake, 11 - tested motor, 12 - one of two inertial wheels attached to shaft on both sides of motor mounted in test-stand, b) physical model

\section{Two-dimensional finite element model}

Despite of significant increase in computers capacity and progress in computational electromagnetism, computations of the eddy current problems in three-dimensional domain is still a difficult and time-consuming task. This is why in eddy-current analysis it is always 
justified to carry out preliminary computations using a two-dimensional numerical model prior to involving comprehensive, but costly three-dimensional approaches.

Table 1. Selected parameters of the designed and manufactured brake

\begin{tabular}{l|c}
\hline Rated current & $I_{N}=10 \mathrm{~A}$ \\
\hline Pole-pairs & $p=2$ \\
\hline Rotor outer diameter & $D_{r}=56 \mathrm{~mm}$ \\
\hline Rotor inner diameter & $D_{i}=19 \mathrm{~mm}$ \\
\hline Rotor length & $L_{z}=11 \mathrm{~mm}$ \\
\hline Rotor material mild steel conductivity at $20^{\circ} \mathrm{C}$ & $\sigma=5.74 \mathrm{MS} / \mathrm{m}$ \\
\hline Air-gap length & $\delta=2 \mathrm{~mm}$ \\
\hline Rated torque at speed $10 \mathrm{krpm}$ & $T_{N}=0.14 \mathrm{~N} \cdot \mathrm{m}$ \\
\hline
\end{tabular}

a)

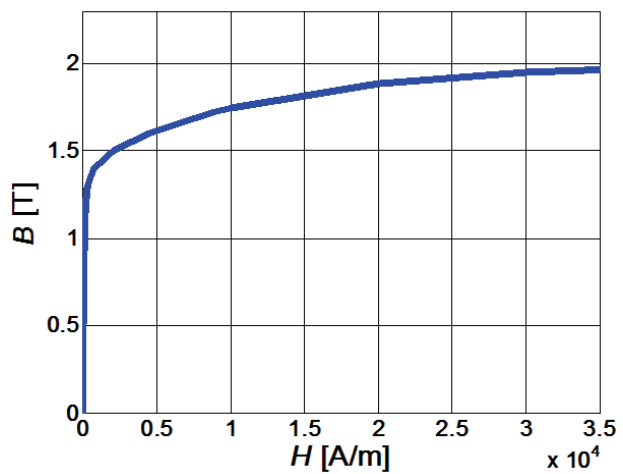

b)

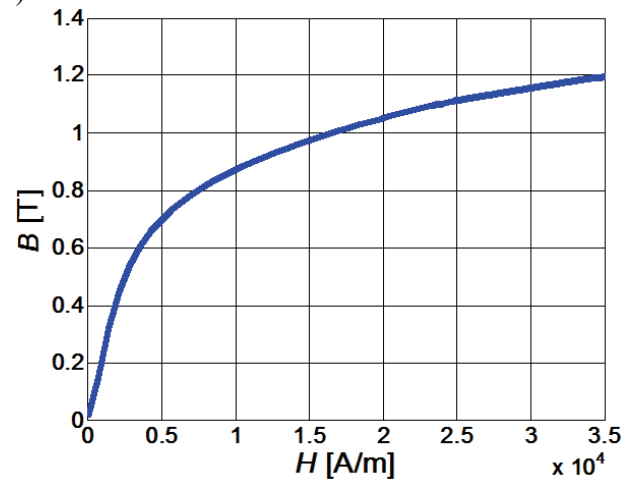

Fig. 2. Magnetization curves: a) stator, b) rotor

Modeling electromechanical converters equipped with solid rotors by use of two-dimensional numerical models requires taking account for the rotor end-effects associated with current density vector components that are perpendicular to the shaft [15-18]. In such a case it is a common practice to replace in computations physical conductivity of the material with an effective conductivity being the product between the real conductivity and the so-called endrotor factor obtained by means of either analytical or numerical methods [15-18]. It is supposed that for the system considered here such an approximation will be too rough, although the most geometrically justified and, so easily interpretable formula given by O'Kelly will be used here [16]:

$$
k_{e}=\frac{L_{z}}{L_{z}+\tau},
$$

to which we add the interpretation of $\tau$ as length of the arc on the rotor surface for whose chord is equal to the stator tooth width. Here, (1) gives value of 0.52 . The electromagnetic field distribution in the considered two-dimensional numerical model is governed by equation: 


$$
-\nabla^{2} A_{z}=\mu J_{S z}-\mu k_{e} \sigma \frac{\mathrm{d} A_{z}}{\mathrm{dt}},
$$

where $A_{z}, J_{S z}$ - are components of magnetic vector potential and excitation current density in directions parallel to $z$-axis respectively, $\mu$ - magnetic permeability. The magnetization characteristics of brake materials are shown plotted in Figure 2. These were measured using a digital fluxmeter Lakeshore M480 and a PC-controlled current source. The analysis neglects the impact of hysteresis phenomenon on the torque produced, which will be small due to relatively narrow hysteresis loop of mild steel and small effective rotor volume related with a very small penetration depth of rotor by the magnetic field.

Discretization of Equation (2) was carried out using first order triangular finite elements, standard Galerkin procedure and the implicit Euler scheme for discretization in the domain of time [19]. The rotor movement was modeled using the moving band technique [19]. Finite element mesh and an example of magnetic field distribution computed using the elaborated model are shown depicted in Figure 3.

a)

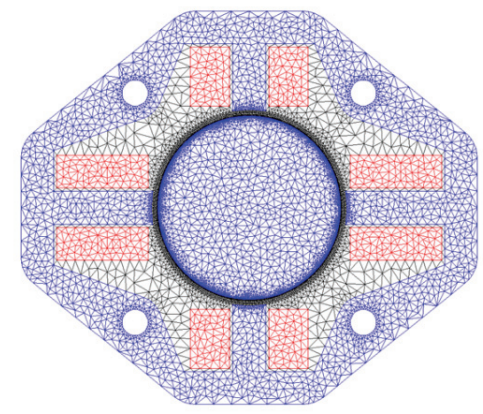

b)

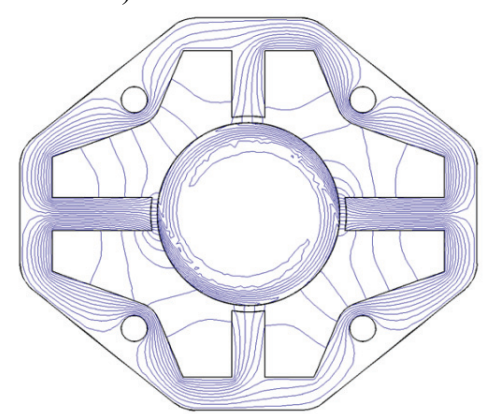

Fig. 3. Two-dimensional numerical model of the brake: a) finite element mesh, b) example of magnetic field distribution at nominal conditions of operation

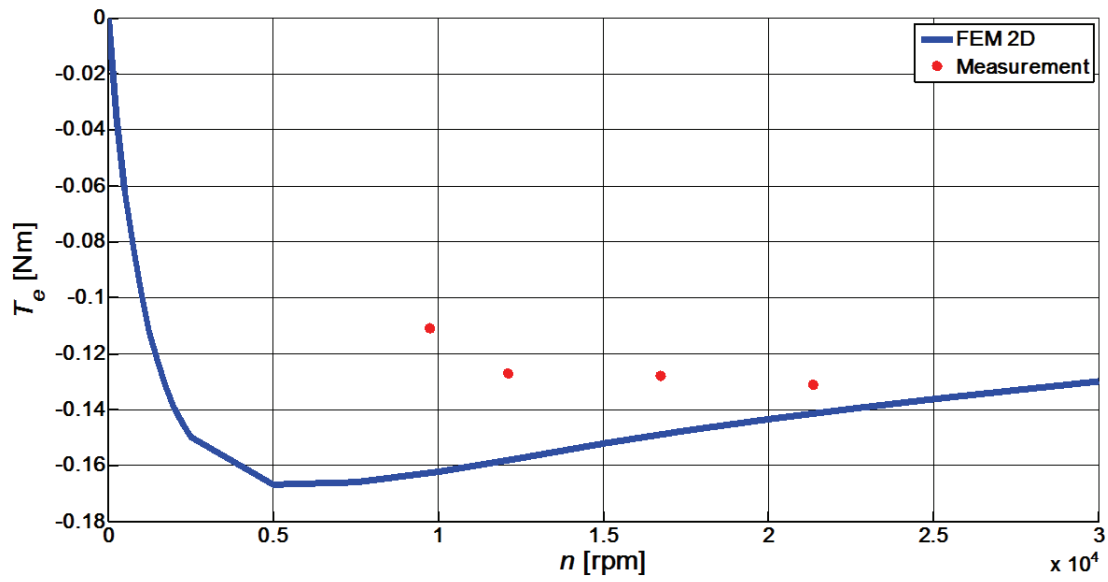

Fig. 4. Comparison of results of computations carried out using two-dimensional finite-element model with measurements carried out on the physical model 
Using the elaborated finite element model, the steady-state torque-speed characteristic was computed for rated supply conditions and compared with the results of measurement carried out on the physical model (see Fig. 4). From the analysis of results it can be seen that discrepancy between results of computation and those measured on physical model is significant. This is especially at low speed, which suggests that the influence of rotor-end effects is high, as expected, but at the same time there is no guidelines available on how to estimate effective conductivity in such a case. The results of this analysis show that two-dimensional model of the considered system is too inaccurate to be applicable in design investigations.

\section{Three-dimensional finite element model}

For three-dimensional modeling the Flux-3d FEA package was used. The discretization mesh of the three-dimensional model is shown in Figure 5 (due to symmetry in the field distribution the computational domain was reduced by one- fourth). Using this model the transient analysis with forced speed was carried out, and after reaching the steady-state the torque-speed characteristic was determined and compared with the previous results from the two-dimensional model and measurement (Fig. 6). As it can be seen using the threedimensional model delivers a much more accurate predictions in the entire range of rotational speed, hence it is more justified to use this model in further analysis, although its execution time compared to that of the two-dimensional one is like 43 to 1 .

Fig. 5. Finite element mesh of brake for threedimensional model considering model symmetry (senses of main fluxes are shown by arrows)

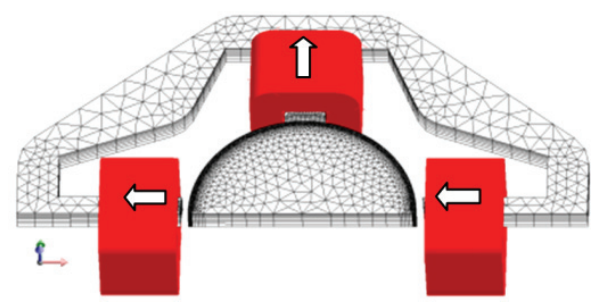

The analysis of influence of the rotor construction on steady-state torque-speed characteristics of the investigated converter was carried out for the following scenarios:

1)Influence of the number of the rotor slits while keeping constant their dimensions.

2) Influence of the rotor slits depth while keeping their number constant.

3) Influence of thickness of the copper layer coated the rotor while keeping its outer diameter constant.

4) Influence of the rotor length at rated speed.

For the solid-rotor induction machines the simplest and the most often used method for improving the performance is to use axial slits on the rotor surface. These increase depth of rotor penetration by the magnetic field making it possible to achieve the torque as twice high in comparison with the machine equipped with a uniform (unslitted) rotor [4, 13]. The influence of slits dimensions and their number on performance of the solid-rotor induction 
machines was studied in details in the literature $[4,13]$. It has been observed that from the point of view of the electromagnetic quantities the depth of the slits should be as high as possible, whilst relationship involving their optimal number is complex and finding out one should be done specifically for the machine considered.

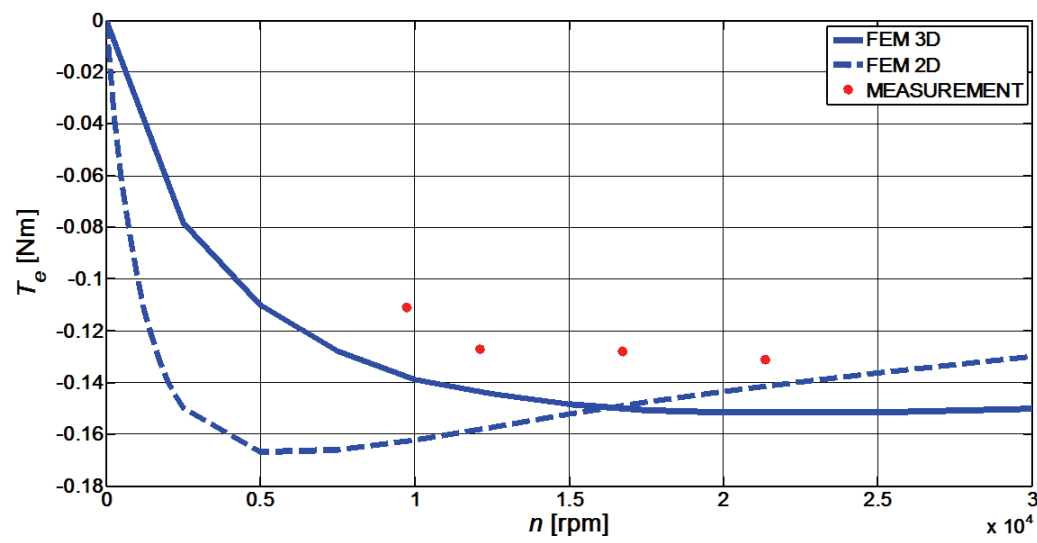

Fig. 6. Comparison of the results of steady-state torque-speed characteristic computation using threedimensional model with the results obtained by means of the two-dimensional model and measurement

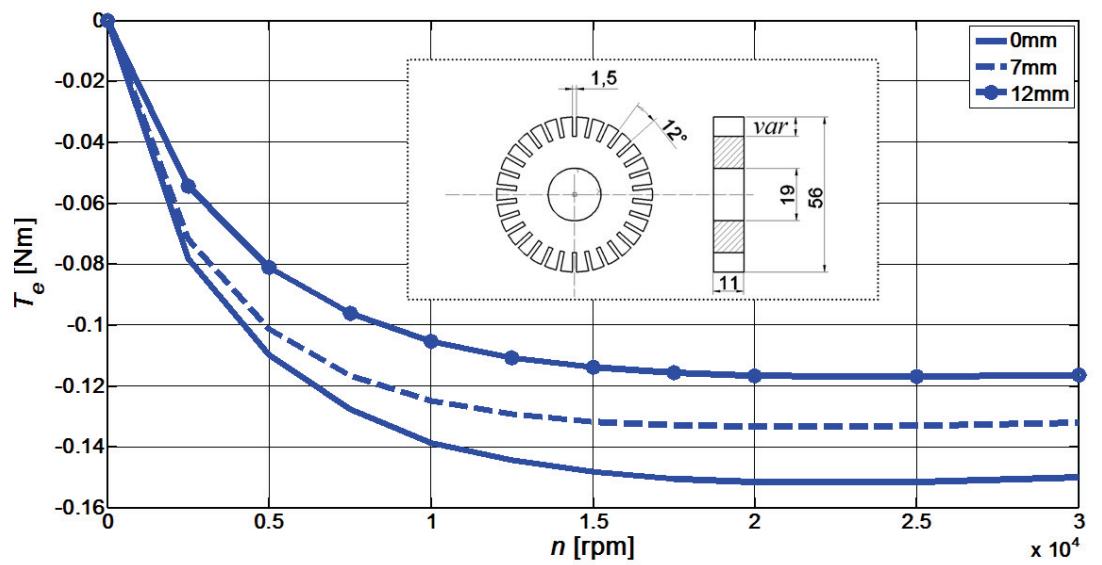

Fig. 7. Steady-state torque-speed characteristics for various slit depths (number of slits equal to 30)

For the brake investigated the results of analysis of influence of the rotor slits depth and their number are shown plotted in Figures 7 and 8. From the analysis of those results the following conclusions can be drawn.

For the range of rotational speed considered it is observed that the torque decreases with increase of the slits depth. This relationship differs significantly from that for the solid-rotor induction motors where increase of the slits depth always results in increase of the average torque. The main reason of this variation is that the DC current-fed brake operates in conditions equivalent to unity slip at very high excitation frequency. 


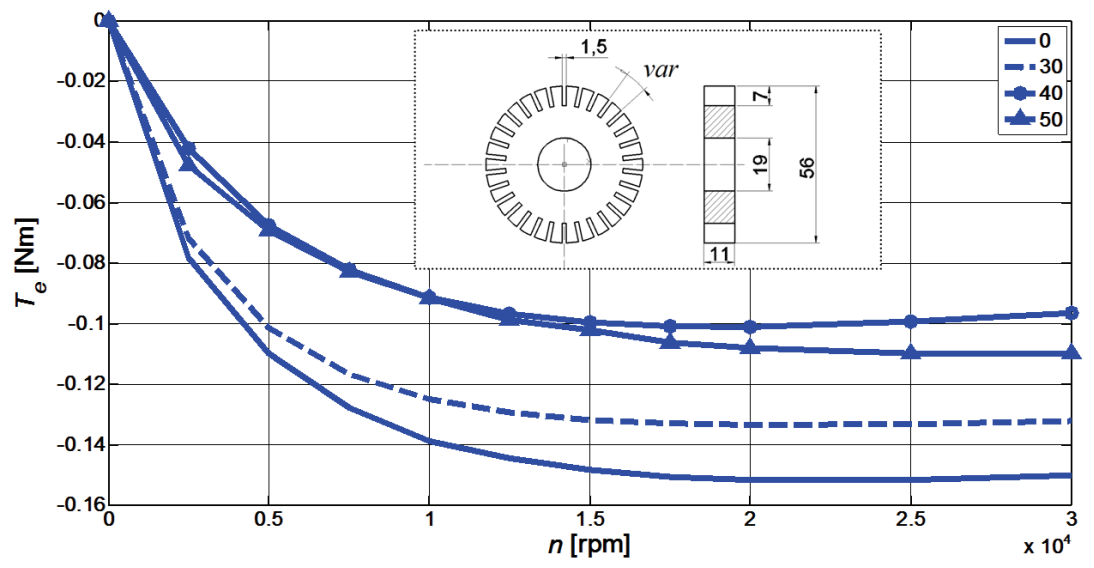

Fig. 8. Steady-state torque-speed characteristics for various numbers of axial slits

a)

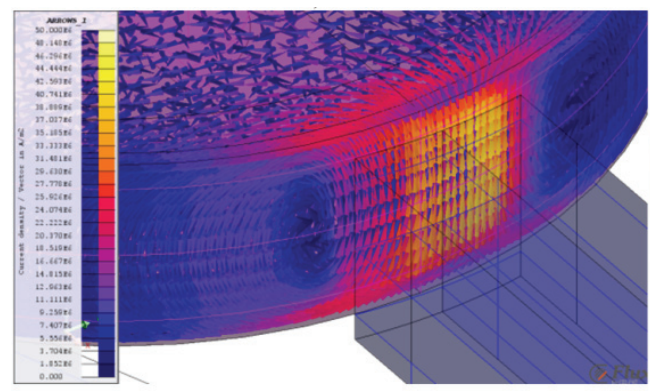

c)

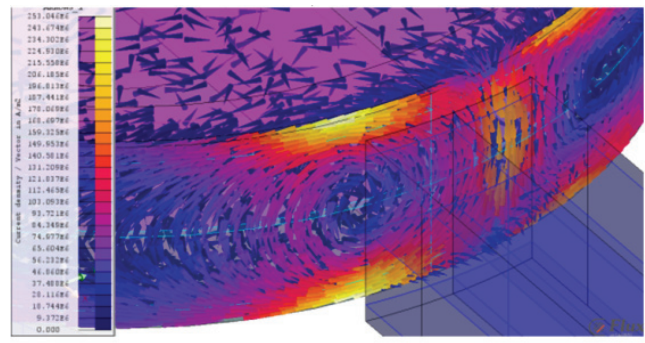

d) b)

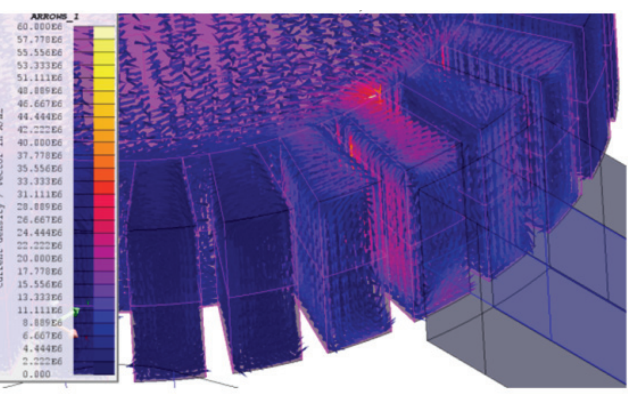

Fig. 9. Comparison of current density vector distributions induced in rotors at rated conditions of operation: a) uniform rotor, b) slitted rotor with slits depth equal to $12 \mathrm{~mm}$, c) rotor coated by $1 \mathrm{~mm}$ thick copper layer, d) uniform rotor of length equal to $17 \mathrm{~mm}$.

A very small penetration depth of rotor surface by the magnetic field (see Fig. 9a, b) does not allow the current density to "fall" beyond the slit zone, and slitting results practically only in reduction of rotor volume. To make the slitting effective, one would have to make the slits thinner than one-fourth of millimeter and in a very large number. This is, however technically complex and expensive. 


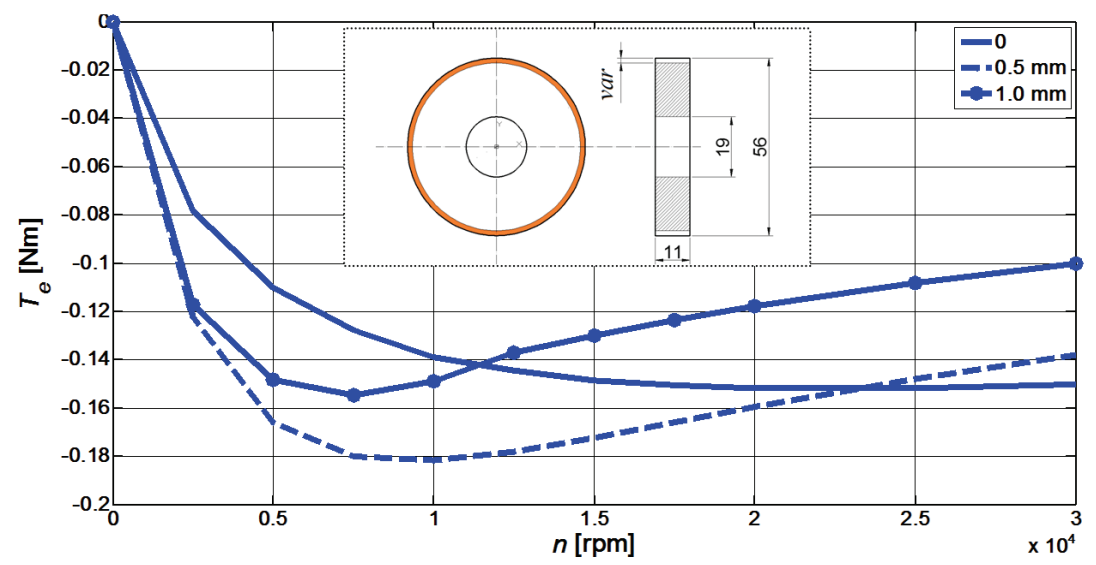

Fig. 10. Steady-state torque-speed characteristics for various thickness of copper coating

From the analysis of the influence of the number of slits it can be noticed that increase in the number of slits results in decrease in the braking torque, but if the number of slits is greater than 40 its value increases again, although for all slitted rotors investigated the braking torque decreases in comparison to the uniform one.

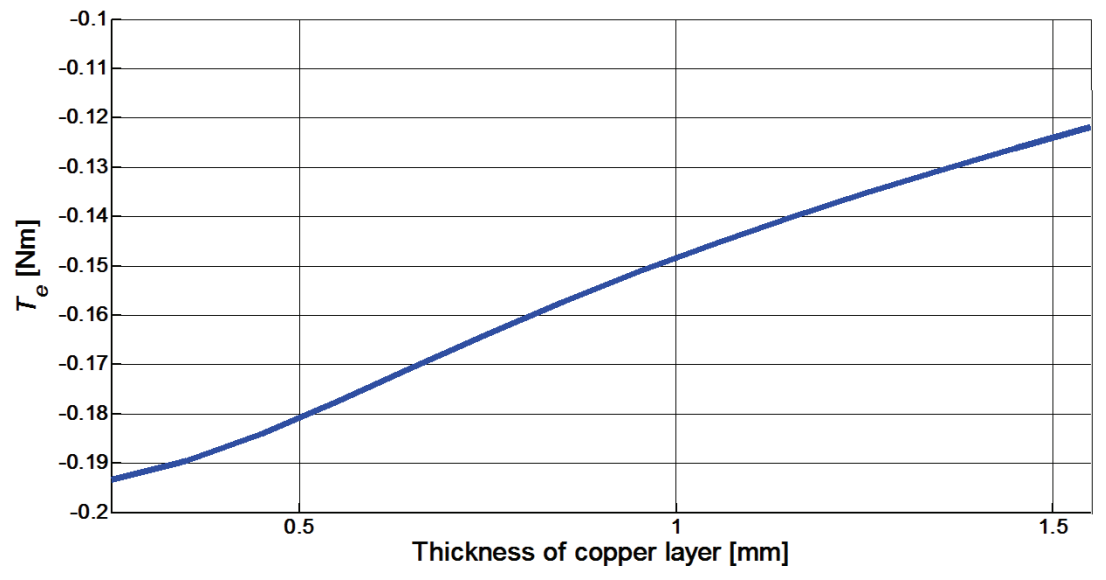

Fig. 11. Braking torque vs. thickness of copper coating at rated speed

The other method used for improving performance characteristics of the solid-rotor induction motors is coating the rotor surface by a thin layer of highly conducting materials such as copper, aluminum or brase [4]. In case of the solid-rotor induction machines this modification makes possible to reduce losses due to higher harmonics of flux density in the air-gap $[4,14]$. From computations of eddy-current density shown depicted in Figure $9 \mathrm{c}$ and results plotted in Figure 10 a very high complexity of phenomenon can be deduced. At rated speed use of the copper coating, while keeping the air-gap length constant, allowed for rise of the braking torque only for a very thin coatings being smaller than $1 \mathrm{~mm}$. (see Fig. 11). The main 
reason of decrease in torque value, when the thickness of coating is thicker, is weakening of the main flux by reaction flux developed in the rotor.

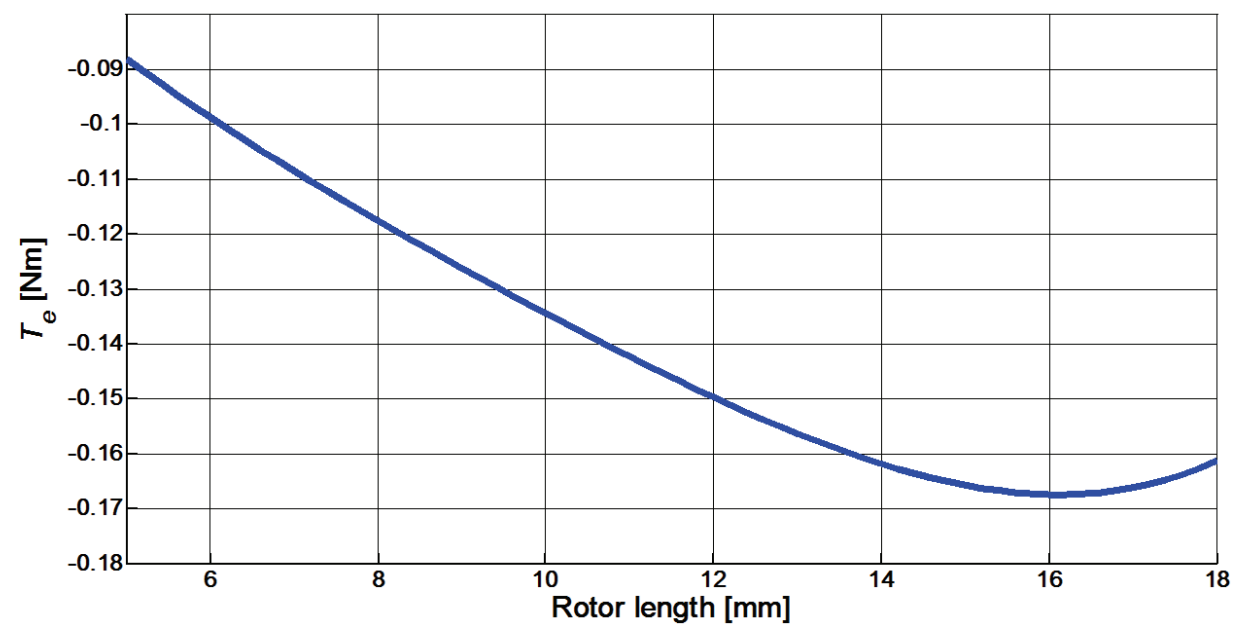

Fig. 12. Braking torque vs. rotor length at rated speed for the uniform rotor

Except of the cases analyzed above, a very interesting issue was to analyze the influence of the rotor length, while keeping all remaining dimensions constant. In physical model the rotor length is equal to the stator stack length. The characteristic of the braking torque vs. rotor length for rated speed is shown plotted in Figure 12. As it can be seen, increasing the rotor length results in rise of the braking torque. This relationship is associated with increasing the current density vector component parallel to the shaft and "moving" the rotor-end effect beyond the stator stack length (see Fig. 9d). When the rotor length is longer than $16 \mathrm{~mm}$, it can be observed that the braking torque drops down due to rise of rotor equivalent impedance.

\section{Conclusion}

The purpose of this work was to analyze the influence of the rotor construction on the steady-state torque-speed characteristics of the high-speed eddy-current brake. The analysis carried out using the two- and three-dimensional time-stepping finite element model and comparison of computations with measurements carried out on the laboratory test-stand showed inapplicability of a two-dimensional approach. The computations of the performance characteristics for various modifications of the basic rotor design using the three-dimensional model have shown that some relationships obtained already for solid-rotor induction motor do not apply for the solid-rotor DC current-fed induction brakes. In particular it was shown that:

- The presence of the rotor surface axial slits results in decrease of the braking torque.

- Coating rotor with a very thin layer of copper contributes to rise of torque.

- In case of coated rotor it is beneficial to extending the rotor length beyond stator stack length, but the optimal rotor length should be a subject of individual investigations. 


\section{Acknowledgment}

This work was supported by the Polish Ministry of Science and Higher Education under Project No. NN510 700840 .

\section{References}

[1] Rahman M.A., Chiba A., Fukao T., Super high speed electrical machines - summary. Proc. of Power Engineering Society General Meeting, Denver, USA, 10 June, Vol. 2, pp. 1272-1275 (2004).

[2] Arkkio A., Jokinen T., Lantto E., Induction and permanent-magnet synchronous machines for highspeed applications. Proc. of the 8th International Conference on Electrical Machines and Systems (ICEMS 2005), Nanjing, China, 27-29 September, Vol. 2, pp. 871-876 (2005).

[3] Mekhiche M., Kirley J. I., Tolikas M., High speed motor drive development for industrial applications. Proc. of International Conference on Electric Machines and Drives (IEMD'99), Seattle, USA, 9-12 May, pp. 244-248 (1999).

[4] Huppunen J., High-speed solid-rotor induction machine - electromagnetic calculation and design. Ph. D. Diss., ActaUniversitatisLappeenrantaensis, Lappeenranta, 2004, http://www.doria.fi/bitst ream/handle/10024/36551/isbn9517649444.pdf?sequence=1, 04.2014.

[5] McBride W. E., Franks J, $9500 \mathrm{hp} \mathrm{high} \mathrm{speed} \mathrm{motor} \mathrm{driven} \mathrm{compressor.} \mathrm{Proc.} \mathrm{of} \mathrm{Petroleum} \mathrm{and} \mathrm{Che-}$ mical Industry Conference, San Antonio, USA, 11-13 September, pp. 155-163 (2000).

[6] Seok-Myeong J., Han-Wook C., Sang-Kyu C., Design and analysis of a high-speed brushless dc motor for centrifugal compressor. IEEE Transactions on Magnetics, June, 43(6): 2573-2575 (2007).

[7] Srivastava R.K, Kumar S., An alternative approach for calculation of braking force of an eddy-current brake. IEEE Trans. Magn. 45(1): 150-154 (2009).

[8] Sharif S., Sharif K., Influence of skin effect on torque of cylindrical eddy current brake. [In] Proc. Pow. Eng., Energy and Electrical Drives Conf., (POWERENG '09), pp. 535-539 (2009).

[9] Gay S.E., Ehsani M., Parametric analysis of eddy-current brake performance by 3-D Finite-Element analysis. IEEE Trans. Magn. 42(2): 319-328 (2006).

[10] Anwar S., A parametric model of an eddy current electric machine for automotive braking applications. IEEE Trans. Contr. Syst. Tech. 12(3): $422-427$ (2004).

[11] Batista Dietrich A., Chabu I.E., Cardoso J.R., Eddy-current brake analysis using analytic and FEM calculations - Part II: Application. Proc. of Intern. Electric Machines and Drives Conf. (IEEE IEMDC'2001), pp. 458-461 (2001).

[12] Jagiela M., Kowol M., Kołodziej J. et al., Design, analysis and testing of high-speed eddy-current brake/dynamometer, XXII Symposium Electromagnetic Phenomena in Nonlinear Circuits, EPNC 2012, June 26-29, Pula, Croatia, pp. 19-20 (2012).

[13] Aho T., Nerg J., Pyrhönen J., The effect of the number of rotor slits on the performance characteristics of medium-speed solid rotor induction motor. Proc. of the 3rd IET International Conference on Power Electronics, Machines and Drives (PEMD 2006), Dublin, Ireland, 4-6 April, pp. 515-519 (2006).

[14] Aho T., Nerg J., Pyrhönen J, Analyzing the effect of the rotor coating on the rotor losses of mediumspeed solid-rotor induction motor. Proc. of International Symposium on Power Electronics, Electrical Drives, Automation and Motion (SPEEDAM 2006), Taormina, Italy, 23-26 May, pp. 103-107 (2006).

[15] Jagieła M., Garbiec T., Evaluation of rotor-end factors in the solid rotor induction motors. IEEE Transactions on Magnetics, January, Vol. 48(1): 137-142 (2012).

[16] O'Kelly D., Theory and performance of solid-rotor induction and hysteresis machines. IEE Proc., May 123(5): 421-428 (1976).

[17] Aho T., Nerg J., Pyrhönen J., Experimental and finite element analysis of solid rotor end effects. IEEE International Symposium, Vigo, Spain, 4-7 June, pp. 1242-1247 (2007).

[18] Gieras J.F., Saari J., Performance calculation for a high speed solid-rotor induction motor. Proc. of 36th IEEE Annual Conference on Industrial Electronics Society (IECON 2010), Glendale, USA, 7-10 November, pp. 1748-1753 (2010).

[19] Demenko A., Field approach to the simulation of electric machine dynamics. Poznan University of Technology Press, Poznan, 1997 (in Polish). 